\title{
Charge Transport in 1-D Nanostructured CdS Dye Sensitized Solar Cell
}

\author{
M. Ragam, ${ }^{1}$ N. Sankar, ${ }^{2}$ and K. Ramachandran ${ }^{3}$ \\ ${ }^{1}$ Department of Physics, Fatima College, Madurai 625014, India \\ ${ }^{2}$ Department of Physics, Yadava College, Madurai 625014, India \\ ${ }^{3}$ School of Physics, Madurai Kamaraj University, Madurai 625 021, India \\ Correspondence should be addressed to M. Ragam; ragamyc1983@yahoo.com
}

Received 26 March 2013; Revised 21 August 2013; Accepted 22 August 2013

Academic Editor: Liqiang Jing

Copyright (C) 2013 M. Ragam et al. This is an open access article distributed under the Creative Commons Attribution License, which permits unrestricted use, distribution, and reproduction in any medium, provided the original work is properly cited.

Charge transport in eosin yellow sensitized CdS 1-D nanostructures is studied. Direct conduction pathway for electron transport in nanowires enhances $V_{\text {oc }}$ in CdS nanowires compared to nanorods and nanoparticles. $J-V$ characterization of nanowires results in improved efficiency of $0.184 \%$ due to fewer interparticle connections. Increase in $J_{\mathrm{sc}}$ is observed by coating CdS 1-D nanostructures on $\mathrm{TiO}_{2}$ substrate which reduces rate of recombination and photocorrosive nature of CdS photoanodes. Enhancement in efficiency up to $0.501 \%$ is achieved for CdS 1-D nanostructures DSSCs on $\mathrm{TiO}_{2}$ substrate.

\section{Introduction}

Dye sensitized solar cells (DSSCs) offer the hope of fabricating photovoltaic devices with high efficiency at low cost by simple fabricating process, as an alternative to conventional p-n junction photovoltaic device [1]. Recently, cadmium sulphide (CdS) is reported to be an active promising alternative material due to its direct band gap $(2.3 \mathrm{eV})$, corresponding to the spectrum of visible light [2]. In DSSC, the dye adsorbed photoanodic film plays an important role because it serves as a pathway for photoinjected electrons. The overall cell performance strongly depends on the surface and electronic properties of photo anodes [3]. Electron transport in nanoparticles (NPs) based DSSCs occurs by a series of hopping events between trap states on neighboring particles [3, 4], whereas in 1-D nanostructures such as nanorods (NRs), nanowires (NWs) direct conduction pathway of electron transport from the point of generation to the collection electrode maintains high surface area for dye adsorption [5]. Two- to three-fold increase in photo conversion efficiency of CdS nanowires (NWs) $(0.18 \%)$ is observed than CdS nanorods (NRs) $(0.08 \%)$ and CdS nanoparticles (NPs) (0.06\%). Yang et al. [6] reported that 1-D nanostructure including NWs and NRs facilitates photon absorption and electron transport with improved efficiencies. Reda and El-Sherbieny [2] reported fluorescein sensitized CdS NP photoanodes with efficiency of $0.022 \%$ and concluded that the anchoring amino acid groups (basic dyes) present in the CdS surface resist the electron transfer from the excited state to the conduction band of CdS which suppressed the photoelectric conversion. The significant factor to be considered in improving overall solar cell efficiency is the separation of the generated electron-hole pairs. Although exciton generation can be enhanced by using nanoparticles and charge transport by using nanowires, efficient charge separation can be achieved by exploiting a heterojunction between two different materials [7]. A pair of materials can be chosen so that the band alignment is favorable for charge separation. Recently, solar cells made of both quantum dots and nanowires having staggered band alignment were demonstrated with CdSe quantum dot (QD) sensitized $\mathrm{ZnO}$ NW operated at an efficiency of $0.4 \%$ [8]. Now a days, $\mathrm{TiO}_{2}$ NPs associated with CdS are used in electrochemical solar cells [9]. The conduction band of CdS is comparatively higher than the electron transporting $\mathrm{TiO}_{2}$ layer, facilitating the passage of photogenerated electrons into the photoanode and impeding the back transfer of electrons to a great extent. 
When CdS 1-D nanostructures on $\mathrm{TiO}_{2}$ substrate come in contact with the electrolyte, photo anodic corrosion can be prevented to a great extent when covered by dye molecules. Hence we expect improved energy-conversion efficiency in eosin yellow (EY) sensitized CdS 1-D nanostructures on $\mathrm{TiO}_{2}$ substrate. Here it is aimed to improve the performance of CdS DSSCs by employing $\mathrm{TiO}_{2}$ substrate to reduce the recombination and thereby enhance its efficiency.

\section{Experiment Details}

\subsection{Synthesis of CdS 1-D Nanostructures}

2.1.1. CdS NPs. Synthesis of CdS NPs is done by chemical method. To start with, $0.015 \mathrm{M}$ aqueous solution of $\mathrm{CdCl}_{2} \cdot 2 \mathrm{H}_{2} \mathrm{O}$ and thioglycerol $\left(\mathrm{C}_{3} \mathrm{H}_{8} \mathrm{O}_{2} \mathrm{~S}\right)$ solution are added with constant stirring for one hour. To this solution sodium sulphide $\left(\mathrm{Na}_{2} \mathrm{~S} \cdot x \mathrm{H}_{2} \mathrm{O}\right)$ is dropwise added. CdS NPs begin to precipitate. The precipitate of CdS is insoluble in water and is thoroughly washed in double distilled water, centrifuged and then air dried at $80^{\circ} \mathrm{C}$ for 6 hours to obtain CdS NPs.

2.1.2. CdS NRs. CdS NRs are prepared by the following procedure. $0.16 \mathrm{M} \mathrm{CdSO}_{4}$ solution is first added to $7.5 \mathrm{M}$ $\mathrm{NH}_{4} \mathrm{OH}$ solution under constant stirring. Following this, $0.6 \mathrm{M}$ thiourea solution is slowly added to the mixture with rigorous stirring. The bath temperature and $\mathrm{pH}$ are maintained at about $65^{\circ} \mathrm{C}$ and 10 , respectively. A yellow precipitate formed is centrifuged and dried in the microwave oven at $65^{\circ} \mathrm{C}$ for 4 hours to obtain CdS NRs.

2.1.3. CdS NWs. CdS NWs are synthesized by following the procedure reported by $\mathrm{Xu}$ et al. [10]. $1 \mathrm{mM}$ of cadmium acetate $\left(\mathrm{Cd}(\mathrm{OAc})_{2} \cdot 2 \mathrm{H}_{2} \mathrm{O}\right)$ and $2 \mathrm{mM}$ of sodium bis(diethyldithiocarbamato) $\left(\mathrm{NaS}_{2} \mathrm{CNEt}_{2} \cdot 3 \mathrm{H}_{2} \mathrm{O}\right)$ are introduced into a mixed solvent of ethylenediamine $\left(\mathrm{C}_{2} \mathrm{~N}_{2} \mathrm{H}_{8}\right)$ and dodecanethiol $\left(\mathrm{C}_{12} \mathrm{H}_{25} \mathrm{SH}\right.$ ) (with volume of 17 and $3 \mathrm{~cm}^{3}$, resp.). After 5 minutes of stirring, the resulting reaction mixture is transferred into a teflon-lined stainless autoclave (50 $\mathrm{cm}^{3}$ capacity). The autoclave is sealed and maintained in a microwave oven at $180^{\circ} \mathrm{C}$ for 48 hours and then cooled to room temperature naturally. The product is collected and washed with distilled water and absolute ethanol several times and then dried in air at $50^{\circ} \mathrm{C}$ for 4 hours.

2.1.4. Preparation of CdS Photoanodes. Thin photoanode films are fabricated using synthesized CdS 1-D nanostructures by employing doctor blade technique [11]. CdS 1-D nanostructures are ground by a mortar and pestle with addition of appropriate amount of distilled water, and acetyl acetone. After making a viscous paste, it is further diluted with distilled water and then few drops of triton X-100 are added for better adhesion of paste on conducting substrate. The paste is spread on the conducting substrate with a glass rod using an adhesive tape as spacers. After drying in air, the films are sintered for $30 \mathrm{~min}$ at $50^{\circ} \mathrm{C}$ in air. After sintering, the CdS films are immersed in $0.5 \mathrm{mM}$ of EY ethanol dye solution for $24 \mathrm{~h}$. To minimize the adsorption of impurities

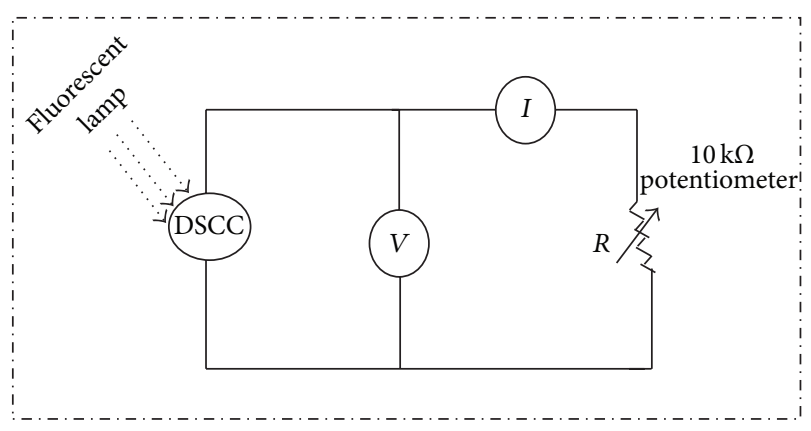

Figure 1: Schematic representation of the circuit designed for current-voltage measurements.

from moisture in the ambient air, the electrodes are dipped in the dye solution while they are still warm at $50^{\circ} \mathrm{C}$. The dye sensitized electrodes are then rinsed with ethanol to remove excess of unanchored dye molecules on the surface.

2.1.5. CdS Photoanodes on $\mathrm{TiO}_{2}$ Substrate. Commercial $\mathrm{TiO}_{2}$ (3 g; P25, Degussa) is mixed with acetyl acetone, Triton X100 , and water. $10 \%$ PEG 20,000 (by weight) was subsequently added on the paste. $\mathrm{TiO}_{2}$ paste is then spread on Indium doped tin oxide (ITO) coated glass substrates using doctor blade method. The film is annealed at $450^{\circ} \mathrm{C}$ for 30 minutes in air. The thickness of $\mathrm{TiO}_{2}$ is about $10 \mu \mathrm{m}$. The prepared paste of CdS 1-D nanostructures is deposited on the $\mathrm{TiO}_{2}$ substrate and annealed at $60^{\circ} \mathrm{C}$ for 20 minutes.

2.1.6. Assembly of DSSC. The platinum coated counter electrode is prepared by spreading a drop of $5 \mathrm{mM}$ chloroplatinic acid hexahydrate $\left(\mathrm{H}_{2} \mathrm{PtCl}_{6}\right)$ in isopropyl alcohol on separate ITO substrate and calcinating it at $450^{\circ} \mathrm{C}$ for $15 \mathrm{~min}$ under air ambient. A liquid electrolyte with redox couple $\mathrm{I}^{-} / \mathrm{I}_{3}{ }^{-}$ is sandwiched between photoanode and counter electrode, pressing firmly. A thin layer of parafilm is used as a spacer to avoid short circuiting between two electrodes. A binder clip is fixed externally to maintain the mechanical grip of the cell without any further sealing, which finalized the assembly of the DSSC.

2.2. Characterizations. Crystallinity and the phase purity of the materials are determined by X-ray diffraction (XRD) recorded at room temperature using PANalytical X'Pert $\mathrm{X}$-ray diffractometer with $\mathrm{Cu}-\mathrm{K} \alpha$ radiation (wavelength: $1.54056 \mathrm{~A}^{\circ}$ ). The morphology, size distribution, and elemental composition of 1-D nanostructures are determined by scanning electron microscope (SEM, JEOL JSM-6390) along with energy dispersive X-ray spectroscopy (EDS, Oxford Instruments, model no. 7582) operating at an accelerating voltage of $20 \mathrm{kV}$. UV-Vis absorption measurements are carried out at room temperature by using UV-Vis absorption spectrometer (Shimadzu-2450). The performance of the DSSC is evaluated from manually recorded photocurrent-photovoltage curves, using a circuit as shown in Figure 1 with $10 \mathrm{k} \Omega$ potentiometer as a variable load and $15 \mathrm{~W}$ fluorescent lamp as light source. 


\section{Results and Discussions}

3.1. X-Ray Diffraction Analysis. Figure 2 shows a typical XRD pattern of the as-synthesized products. The diffraction peaks of CdS NPs, NRs, and CdS NWs can be indexed to hexagonal CdS with lattice constants $a=4.141 \AA$ and $c=6.718 \AA$, in agreement with the literature data (JCPDS card no. 41-1049). The intense and sharp diffraction peaks suggest the obtained products are well crystallized. All the peaks in CdS NWs are highly intense indicating the higher crystallinity. Compared with the JCPDS card, the relative intensities of the peaks corresponding to the (100), (002), (101), (110), and (112) planes are obvious. The (100) diffraction peaks in hexagonal CdS are strong and narrow. It is noticed that the (002) diffraction peaks are extremely strong compared to standard diffraction intensity, which is probably related to the preferential $c$-axis growth of CdS NWs. The mean crystallite size is estimated using Scherrer's equation and is found to be $4 \mathrm{~nm}, 11 \mathrm{~nm}$ and $39 \mathrm{~nm}$ for CdS NPs, NRs, and NWs, respectively. The morphology and dimension of the products are examined by SEM. Typical SEM images of the NPs, NRs, and NWs are shown in Figures 3(a1)-3(a3). The microstructures of individual CdS 1-D nanostructures are investigated in detail by TEM. Figure 3(b1) shows CdS spherical NPs with the average size of $20 \mathrm{~nm}$. Figure $3(\mathrm{~b} 2)$ shows a representative TEM image of single NR with an average diameter of $25 \mathrm{~nm}$ and lengths in the range of $20-40 \mu \mathrm{m}$, and NWs with a thickness of $20 \mathrm{~nm}$ are shown in Figure 3(b3).

3.2. UV-Vis Absorption Analysis. The absorption spectra of synthesized CdS NPs, NRs, and NWs are presented in Figure 4. All the samples show strong UV absorption and high transparency in visible region. In our results, all the samples have a steep absorption edge, similar to the results obtained from the Tauc equation [12]. The absorption band of CdS 1-D nanostructures appears approximately at $451 \mathrm{~nm}$, $475 \mathrm{~nm}$ and $545 \mathrm{~nm}$ for CdS NPs, NRs, and NWs, respectively. Band gaps in semiconductor nanomaterials are closely related to the wavelength range absorbed. The absorption band gap energy can be determined by the following equation: $(\alpha h v)^{n}=\left(h v-E_{g}\right)$, where $h v$ is the photon energy, $\alpha$ the absorption coefficient, and $n$ a value that depends on the nature of transition ( 2 for direct allowed transition). The band gap $\left(E_{g}\right)$ is estimated as $2.75,2.61$, and $2.28 \mathrm{eV}$ for CdS NPs, NRs and NWs, respectively.

3.3. Photocurrent-Voltage Characteristics. The current density-voltage $(J-V)$ characteristics for DSSCs constructed using CdS NPs, NRs, and NWs sensitized with EY dyes under illumination condition $\left(41.39 \mathrm{~mW} / \mathrm{cm}^{2}\right)$ are shown in Figure 5. Table 1 summarizes the measured and calculated values obtained from typical $J-V$ curve. From Figure 5, it can be seen that the cell constructed using CdS NWs film gives a clear improvement in $J_{\mathrm{sc}}$ and $\eta(\%)$ over CdS NPs and NRs based DSSC. The fill factor of the fabricated CdS based DSSCs is calculated as follows:

$$
\mathrm{FF}=\frac{J_{M} V_{M}}{J_{\mathrm{sc}} V_{\mathrm{oc}}},
$$

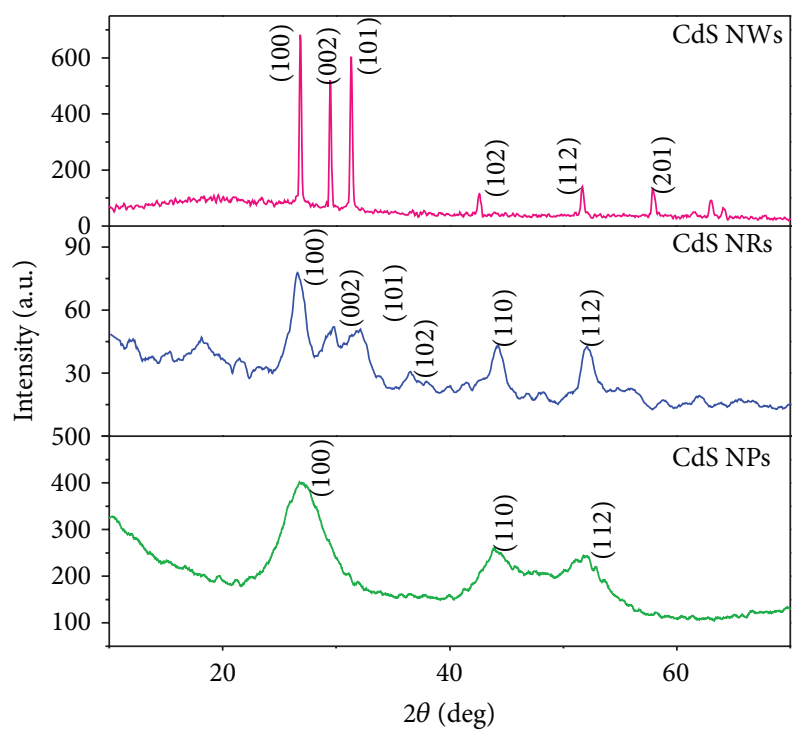

Figure 2: XRD patterns of CdS NPs, CdS NRs, and CdS NWs.

where $J_{M}$ and $V_{M}$ are the current density and voltage, respectively, under maximum output power. According to (1), FF is calculated to be maximum of 0.42 for CdS NWs with $V_{\text {oc }}$ of $0.80 \mathrm{~V}$. It is to be noted that the increase in FF suggests that there is reduction in recombination between the photoexcited carriers in the electrodes and tri-iodide ions in electrolyte. Here, for CdS NPs and NRs, this higher recombination rate results in lower $V_{\mathrm{oc}}$ and FF than NWs. The power conversion efficiency of the fabricated cell is given by

$$
\eta=\frac{J_{\mathrm{sc}} V_{\mathrm{oc}} \mathrm{FF}}{P_{\mathrm{IN}}} \times 100 \%,
$$

where $P_{\mathrm{IN}}$ is the power density of the incident radiation.

According to (2), the solar-to-electric conversion efficiency is obtained as $0.184 \%$ for CdS NWs DSSC. The efficiency depends on the way in which the electron transport takes place from the dye to collecting electrode, that is, on the morphology of semiconducting photoanode materials. It can be seen that the highly ordered 1D NWs provide an ordered pathway for electron transport to the collecting anode, and this is in contrast with the NPs and NRs based DSSC because of highly disordered structure with multiple particle-particle interfaces. Similarly, the contact areas between individual NPs are stronger in NWs than NPs, since the NWs are in situ construction of NPs. The films consisting of NPs and NRs have interconnected porous structure; so during solar cell operation, the electron transport occurs through hopping event between trap states on neighboring particles. However, in an in situ constructed interconnected nanostructure like nanowires, electrons transport takes place by direct conduction pathway from the place of generation to the collector without sacrificing high surface area for dye adsorption.

Recently in 2010, Reda and El-Sherbieny [2] reported the efficiency of DSSCs as $0.02 \%$ for CdS NPs sensitized with fluorescein (FL) dye by employing liquid electrolyte, and the low efficiency was attributed to photoanodic corrosion nature 

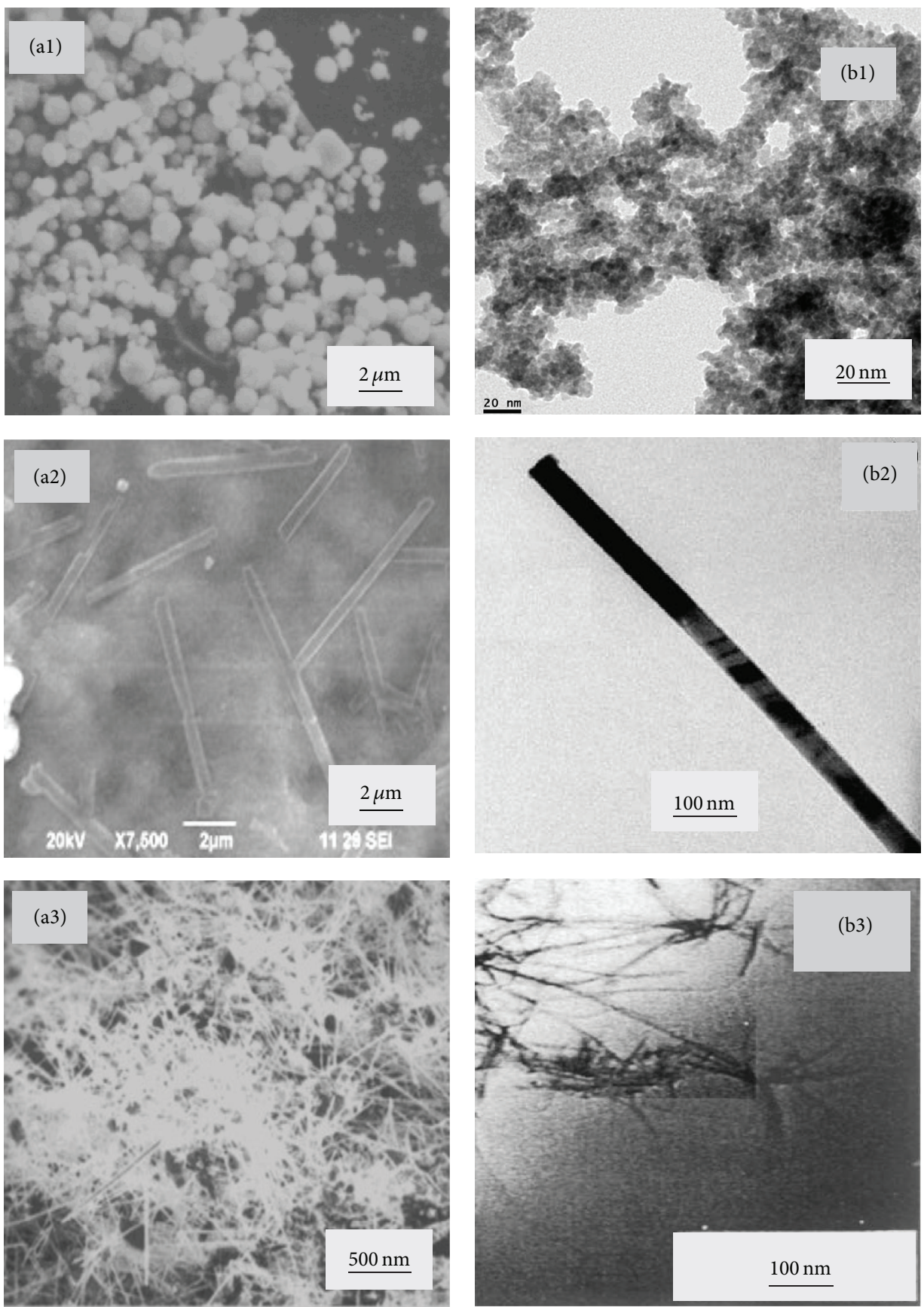

Figure 3: SEM images of (a1) CdS NPs, (a2) CdS NRs and (a3) CdS NWs. TEM images of (b1) CdS NPs, (b2) CdS NRs and (b3) CdS NWs.

of CdS NPs. Vogel et al. [13] reported that photo anodic corrosion processes of the nanoparticles mostly involve surfacetrapped holes, that is, surface bound S-radicals in case of sulfide particles. The holes in CdS 1-D nanostructures can be blocked by coating the 1-D nanostructures with thin layers of wide bandgap materials leading to drastic enhancement of photostability. This implies that holes have to merge through a thin layer of $\mathrm{TiO}_{2}$ before they react with the electrolyte. SEM images and EDS analysis of CdS 1-D nanostructures on the $\mathrm{TiO}_{2}$ substrate are shown in Figure 6. For this configuration,
$J-V$ graphs are again plotted as in Figure 7. At comparable photocurrents, the photovoltages are determined by the difference of the conduction band edge of the substrate and the redox potential of the electrolyte. The photovoltages depend on the size of the nanoparticles and the substrate. The photovoltaic behavior of CdS 1-D nanostructures in $\mathrm{TiO}_{2}$ substrates provides substantial evidence and involvement of $\mathrm{TiO}_{2}$ for increased photocurrent and therein efficiency. The curve corresponding to EY sensitized CdS NWs indicates a short circuit current $\left(J_{\mathrm{sc}}=154 \mu \mathrm{A} / \mathrm{cm}^{2}\right)$, an open circuit 


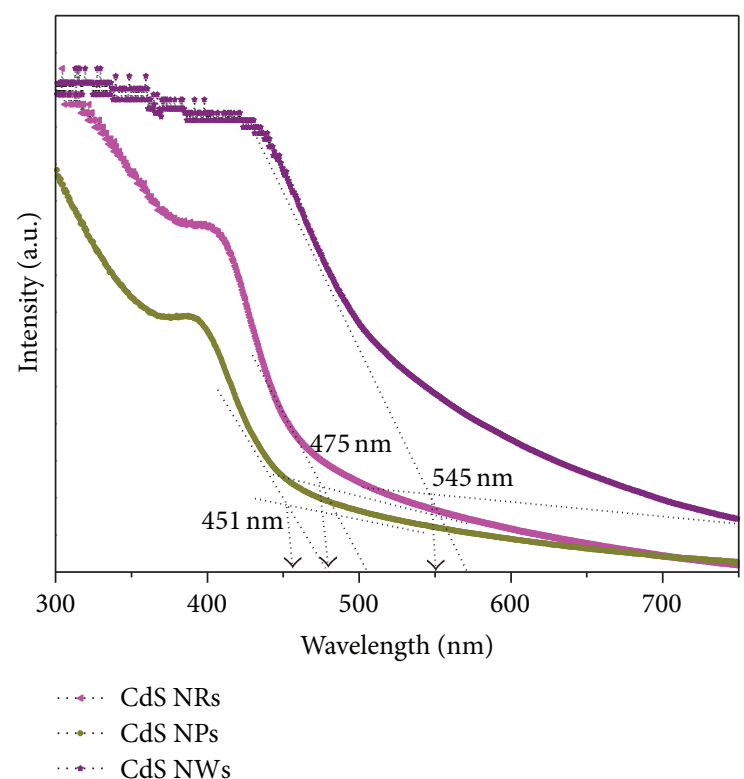

FIgURE 4: UV-Vis absorption spectra of CdS NPs, NRs, and NWs.

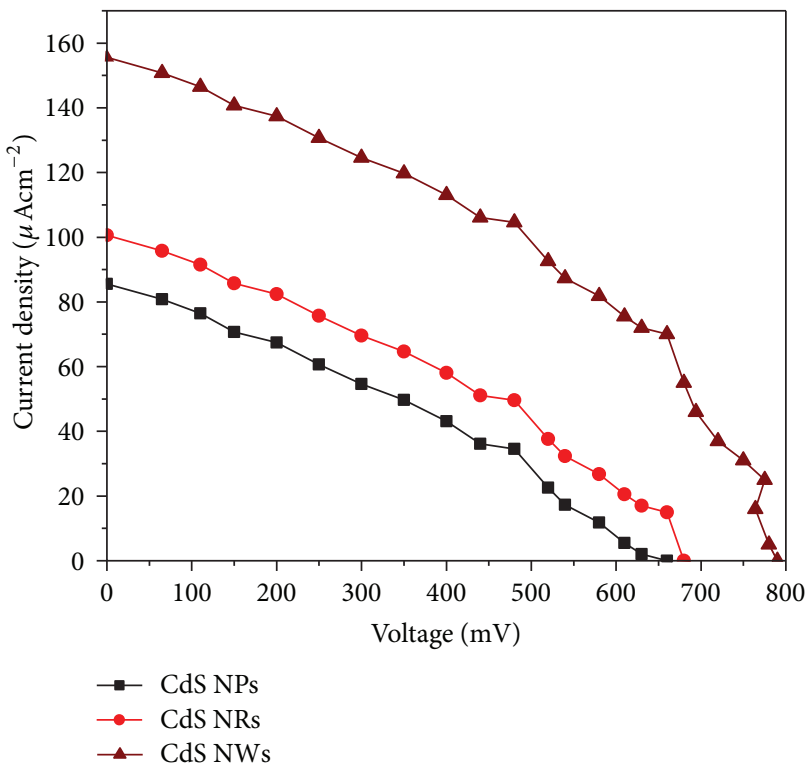

FIGURE 5: Current density-voltage characteristics of EY sensitized CdS NPs, NRs, and NWs DSSCs.

voltage $\left(V_{\mathrm{oc}}=800 \mathrm{mV}\right)$, and fill factor $=0.42$ and $\eta=0.18 \%$ (Table 1). The trend is improved by the incorporation of $\mathrm{TiO}_{2}$ substrates for EY sensitized CdS photoanodes with $J_{\mathrm{sc}}=$ $1210 \mu \mathrm{A} / \mathrm{cm}^{2}, V_{\mathrm{oc}}=650 \mathrm{mV}, \mathrm{FF}=0.25$, and $\eta=0.501 \%$ (Table 2). In the case of EY sensitized $\mathrm{TiO}_{2} / \mathrm{CdS}$ NPs based DSSC, once the injected electrons diffuse through photoanode, its residing time at particle-particle interfaces is more, so as to search for the next easiest path; but the EY sensitized
TABLE 1: Effect of CdS NPs, NRs, and NWs DSSCs.

\begin{tabular}{lcccccc}
\hline Electrode & $\begin{array}{c}J_{\mathrm{sc}} \\
\left(\mu \mathrm{A} \mathrm{cm}^{-2}\right)\end{array}$ & $\begin{array}{c}V_{\mathrm{oc}} \\
(\mathrm{mV})\end{array}$ & $\begin{array}{c}J_{m} \\
\left(\mu \mathrm{A} \mathrm{cm}^{-2}\right)\end{array}$ & $\begin{array}{c}V_{m} \\
(\mathrm{mV})\end{array}$ & FF & $\begin{array}{c}\eta \\
(\%)\end{array}$ \\
\hline CdS NPs & 80 & 650 & 50 & 350 & 0.33 & 0.061 \\
CdS NRs & 100 & 680 & 64 & 400 & 0.37 & 0.089 \\
CdS NWs & 154 & 800 & 104 & 500 & 0.42 & 0.184 \\
\hline
\end{tabular}

TABLE 2: Effect of EY sensitized CdS NPs, NRs, and NWs DSSCs on $\mathrm{TiO}_{2}$ substrate.

\begin{tabular}{lcccccc}
\hline Electrode & $\begin{array}{c}J_{\mathrm{sc}} \\
\left(\mu \mathrm{Acm}^{-2}\right)\end{array}$ & $\begin{array}{c}V_{\mathrm{oc}} \\
(\mathrm{mV})\end{array}$ & $\begin{array}{c}J_{m} \\
\left(\mu \mathrm{Acm}^{-2}\right)\end{array}$ & $\begin{array}{c}V_{m} \\
(\mathrm{mV})\end{array}$ & FF & $\begin{array}{c}\eta \\
(\%)\end{array}$ \\
\hline $\mathrm{TiO}_{2} / \mathrm{CdS} \mathrm{NPs}$ & 520 & 250 & 250 & 120 & 0.23 & 0.031 \\
$\mathrm{TiO}_{2} / \mathrm{CdS} \mathrm{NRs}$ & 700 & 350 & 480 & 220 & 0.43 & 0.376 \\
$\mathrm{TiO}_{2} / \mathrm{CdS} \mathrm{NWs}$ & 1210 & 650 & 600 & 340 & 0.25 & 0.501 \\
\hline
\end{tabular}

$\mathrm{TiO}_{2} / \mathrm{CdS}$ NWs based DSSC easily transports the electrons to the collecting electrode without recombination. It is also seen that the randomly oriented $\mathrm{EY}$ sensitized $\mathrm{TiO}_{2} / \mathrm{CdS}$ NRs have to cross more grain boundaries than $\mathrm{EY}$ sensitized $\mathrm{TiO}_{2} / \mathrm{CdS}$ NWs, which shows slightly lower electron transport rate but not as EY sensitized $\mathrm{TiO}_{2} / \mathrm{CdS}$ NPs. Thus, reduction in electron residing time at trap sites and better electron transport property through interconnected NWs enhances the light harvesting efficiency of EY sensitized $\mathrm{TiO}_{2} / \mathrm{CdS}$ NWs based DSSCs.

The surface recombination has a significant effect on the $J_{\text {sc }}$ and $V_{\text {oc }}$ values of DSSCs. The increase in $V_{\text {oc }}$ value is due to favorable intermediate conduction band levels of CdS 1$\mathrm{D}$ nanostructures, which provides an effective coupling and therefore facilitates fast charge injection kinetics, that is, the electrons injected from the EY dye molecules into CdS 1-D nanostructures, and transfers the electrons to $\mathrm{TiO}_{2}$ substrates rather than direct transfer from CdS 1-D nanostructures to the dye molecules. The holes present in the dye molecules are readily transferred from the dye to the electrolyte $\left(\mathrm{I}^{-} / \mathrm{I}_{3}{ }^{-}\right)$. These findings clearly show that both the particle size and the choice of the appropriate substrate materials are required for an optimal nanoheterojunction. For a more accurate concept of photovoltages and photocurrent quantum yields, the role of traps and relative band edge positions has to be considered.

\section{Conclusions}

In summary, it is possible to improve the efficiency of EY sensitized CdS 1-D nanostructures on the $\mathrm{TiO}_{2}$ substrates. Efficiency as high as $0.501 \%$ is observed for the EY sensitized $\mathrm{TiO}_{2} / \mathrm{CdS} \mathrm{NW}$ electrode in the present strategy. From the morphological point of view, CdS NWs allow easier electron transport because they have fewer interparticle connections compared to CdS NPs and CdS NRs. The higher $\eta$ and $J_{\text {sc }}$ are attributed to the fast transport of electrons through NWs than NTs and NPs. The enhancement in energy conversion 

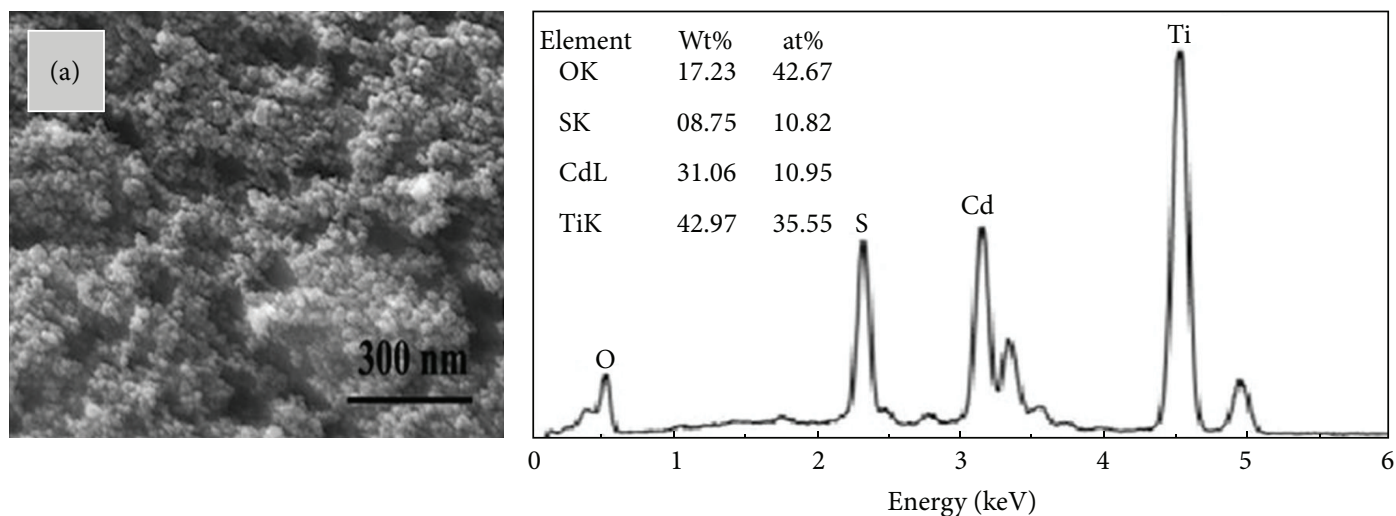

(a)
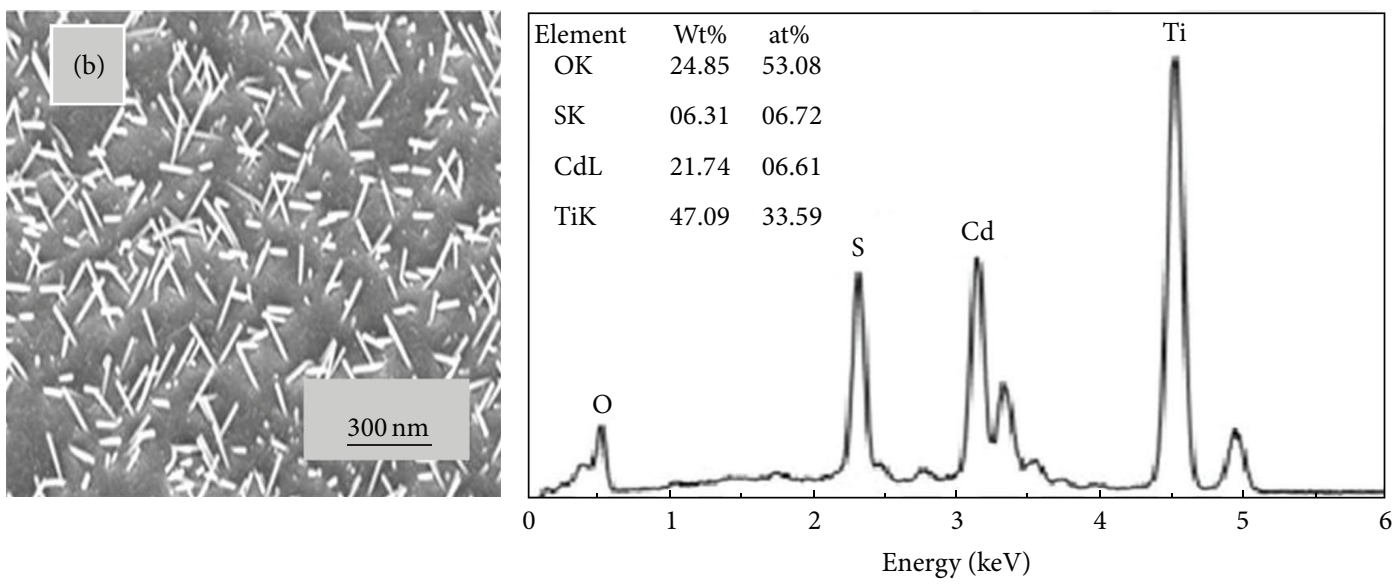

(b)
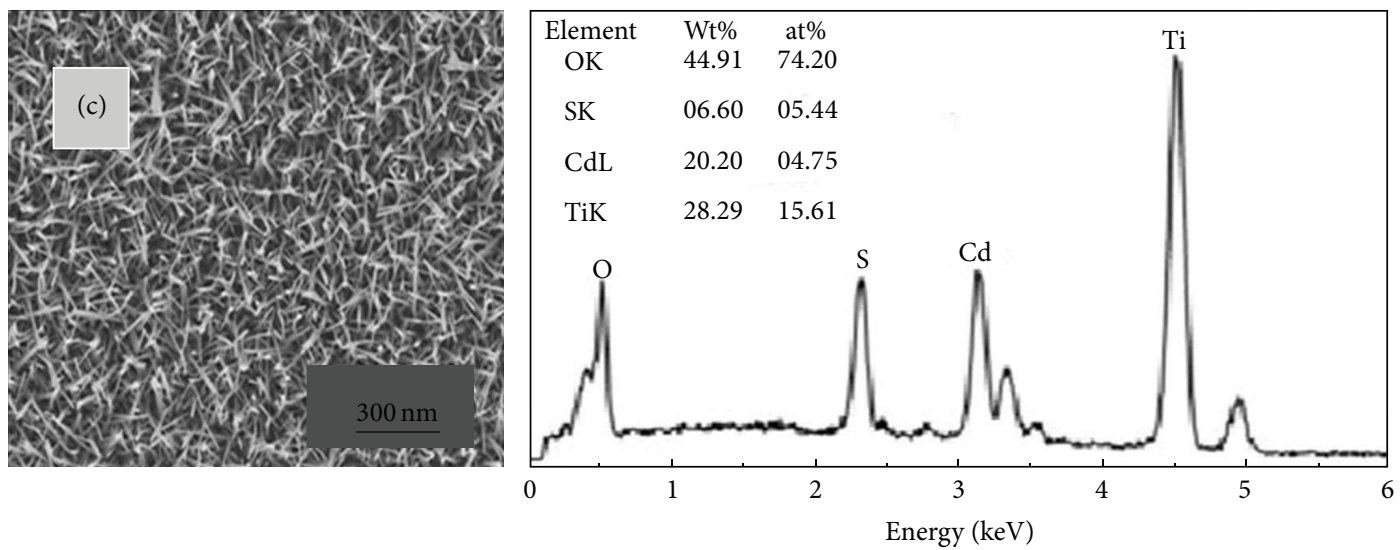

(c)

FIgure 6: SEM images of (a) $\mathrm{TiO}_{2}$-CdS NPs, (b) $\mathrm{TiO}_{2}$-CdS NRs, (c) $\mathrm{TiO}_{2}$-CdS NWs, and corresponding EDS spectra.

efficiency is based on the formation of an interfacial structure capable of inhibiting the recombination of injected electrons.

\section{Disclosure}

The authors certify that there is no direct financial relation with any organization regarding the commercial identities/materials mentioned in the paper.

\section{Acknowledgments}

The first author (M. Ragam) gratefully acknowledges DST, for the research grant under WoS (A) scheme. The author K. Ramachandran acknowledges CSIR-Emeritus, and the authors also acknowledge Dr. Anuradha Ashok, PSG Institute of Advanced Studies, Coimbatore, for TEM measurements and Mr. A. Raja, Central Research Facility Lab, Karunya University, Coimbatore, for SEM analysis. 


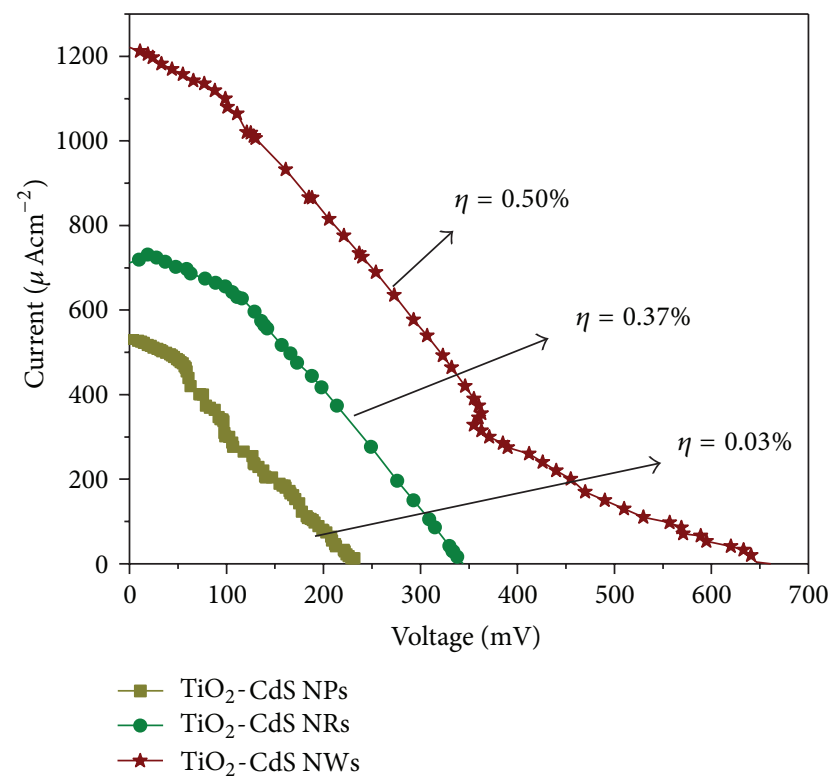

FIGURE 7: Current density-voltage characteristics for EY sensitized CdS NPs, NRs, and NWs on $\mathrm{TiO}_{2}$ substrate.

\section{References}

[1] B. O'Regan and M. Grätzel, "A low-cost, high-efficiency solar cell based on dye sensitized colloidal $\mathrm{TiO}_{2}$ films," Nature, vol. 353, no. 6346, pp. 737-740, 1991.

[2] S. M. Reda and S. A. El-Sherbieny, "Dye-sensitized nanocrystalline CdS and ZnS solar cells with different organic dyes," Journal of Materials Research, vol. 25, no. 3, pp. 522-528, 2010.

[3] N. Kopidakis, E. A. Schiff, N.-G. Park, J. van de Lagemaat, and A. J. Frank, "Ambipolar diffusion of photocarriers in electrolytefilled, nanoporous $\mathrm{TiO}_{2}$," The Journal of Physical Chemistry B, vol. 104, no. 16, pp. 3930-3936, 2000.

[4] E. Galoppini, J. Rochford, H. Chen et al., "Fast electron transport in metal organic vapor deposition grown dye-sensitized ZnO nanorod solar cells," The Journal of Physical Chemistry B, vol. 110, no. 33, pp. 16139-16161, 2006.

[5] A. Ranga Rao and V. Dutta, "Achievement of $4.7 \%$ conversion efficiency in $\mathrm{ZnO}$ dye-sensitized solar cells fabricated by spray deposition using hydrothermally synthesized nanoparticles," Nanotechnology, vol. 19, no. 44, Article ID 445712, 2008.

[6] P. D. Yang, M. Law, L. E. Greene, J. C. Johnson, and R. Saykally, "Nanowire dye-sensitized solar cells," Nature Materials, vol. 4, no. 6, pp. 455-459, 2005.

[7] S. Kim, B. Fisher, H. J. Eisler, and M. Bawendi, “Type-II quantum dots: $\mathrm{CdTe} / \mathrm{CdSe}$ (core/shell) and $\mathrm{CdSe} / \mathrm{ZnTe}$ (core/shell) heterostructures," Journal of the American Chemical Society, vol. 125, no. 38, pp. 11466-11467, 2003.

[8] K. S. Leschkies, R. Divakar, J. Basu et al., "Photosensitization of $\mathrm{ZnO}$ nanowires with $\mathrm{CdSe}$ quantum dots for photovoltaic devices," Nano Letters, vol. 7, no. 6, pp. 1793-1798, 2007.

[9] Y. J. Chi, H. G. Fu, L. H. Qi, K. Y. Shi, H. B. Zhang, and H. T. $\mathrm{Yu}$, "Preparation of YSZ thin films for intermediate temperature solid oxide fuel cells by dip-coating," Journal of Photochemistry and Photobiology A, vol. 357, pp. 195-199, 2008.
[10] D. Xu, Z. Liu, J. Liang, and Y. Qian, "Growth of copper sulfide ultrathin nanowires in a binary surfactant solvent," The Journal of Physical Chemistry B, vol. 109, no. 21, pp. 10699-10704, 2005.

[11] G. Katsaros, T. Stergiopoulos, I. M. Arabatzis, K. G. Papadokostaki, and P. Falaras, "A solvent-free composite polymer/inorganic oxide electrolyte for high efficiency solid-state dye-sensitized solar cells," Journal of Photochemistry and Photobiology A, vol. 149, no. 1-3, pp. 191-198, 2002.

[12] J. Xiao, Y. Li, and A. Jiang, "Structure, optical property and thermal stability of copper nitride films prepared by reactive radio frequency magnetron sputtering," Journal of Materials Science \& Technology, vol. 27, no. 5, pp. 403-407, 2011.

[13] R. Vogel, P. Hoyer, and H. Weller, "Quantum-sized PbS, CdS, $\mathrm{Ag}_{2} \mathrm{~S}, \mathrm{Sb}_{2} \mathrm{~S}_{3}$, and $\mathrm{Bi}_{2} \mathrm{~S}_{3}$ particles as sensitizers for various nanoporous wide-band gap semiconductors," The Journal of Physical Chemistry, vol. 98, no. 12, pp. 3183-3188, 1994. 

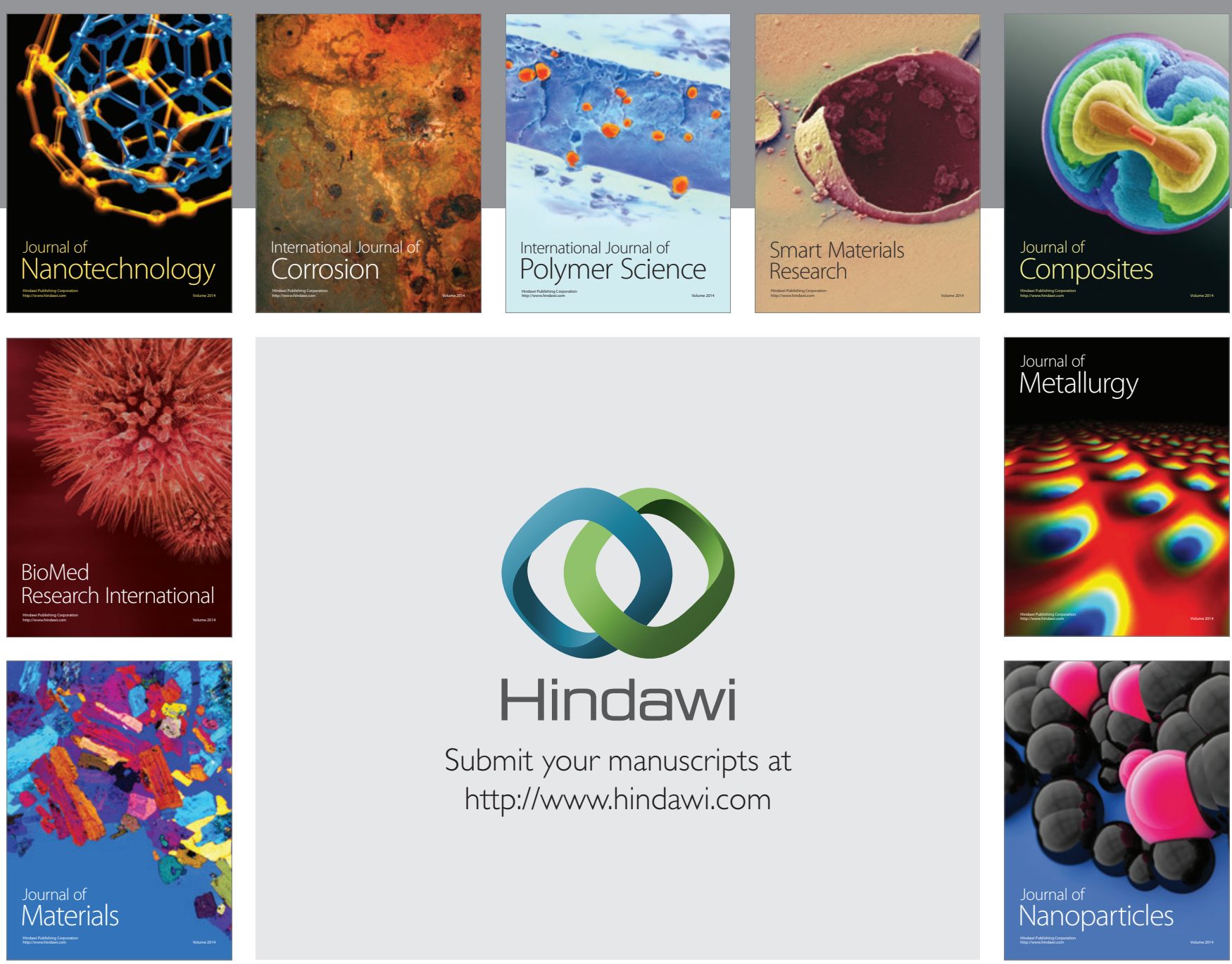

Submit your manuscripts at http://www.hindawi.com
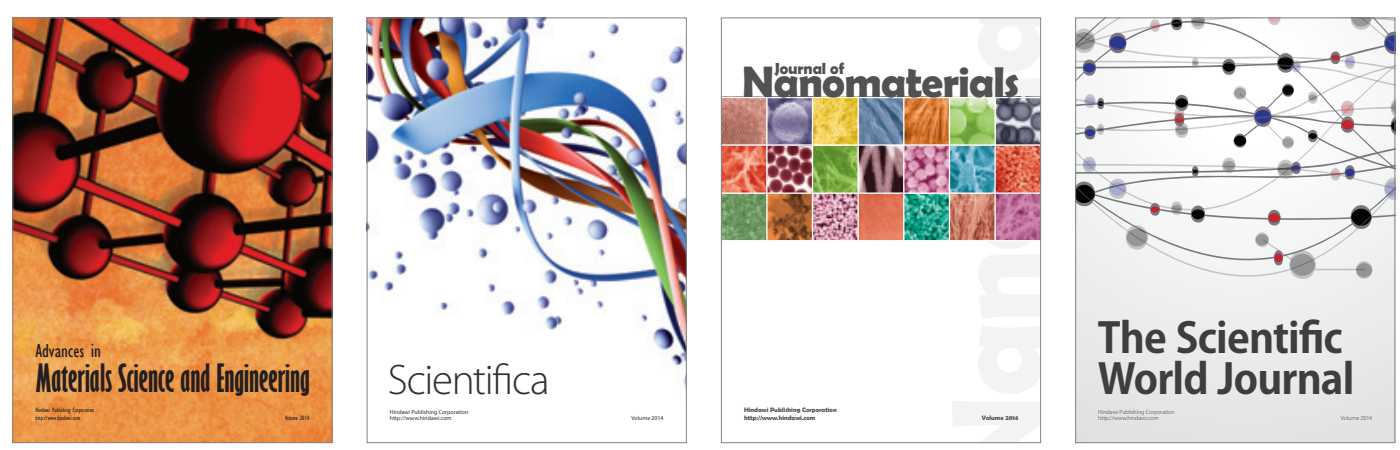

\section{The Scientific World Journal}
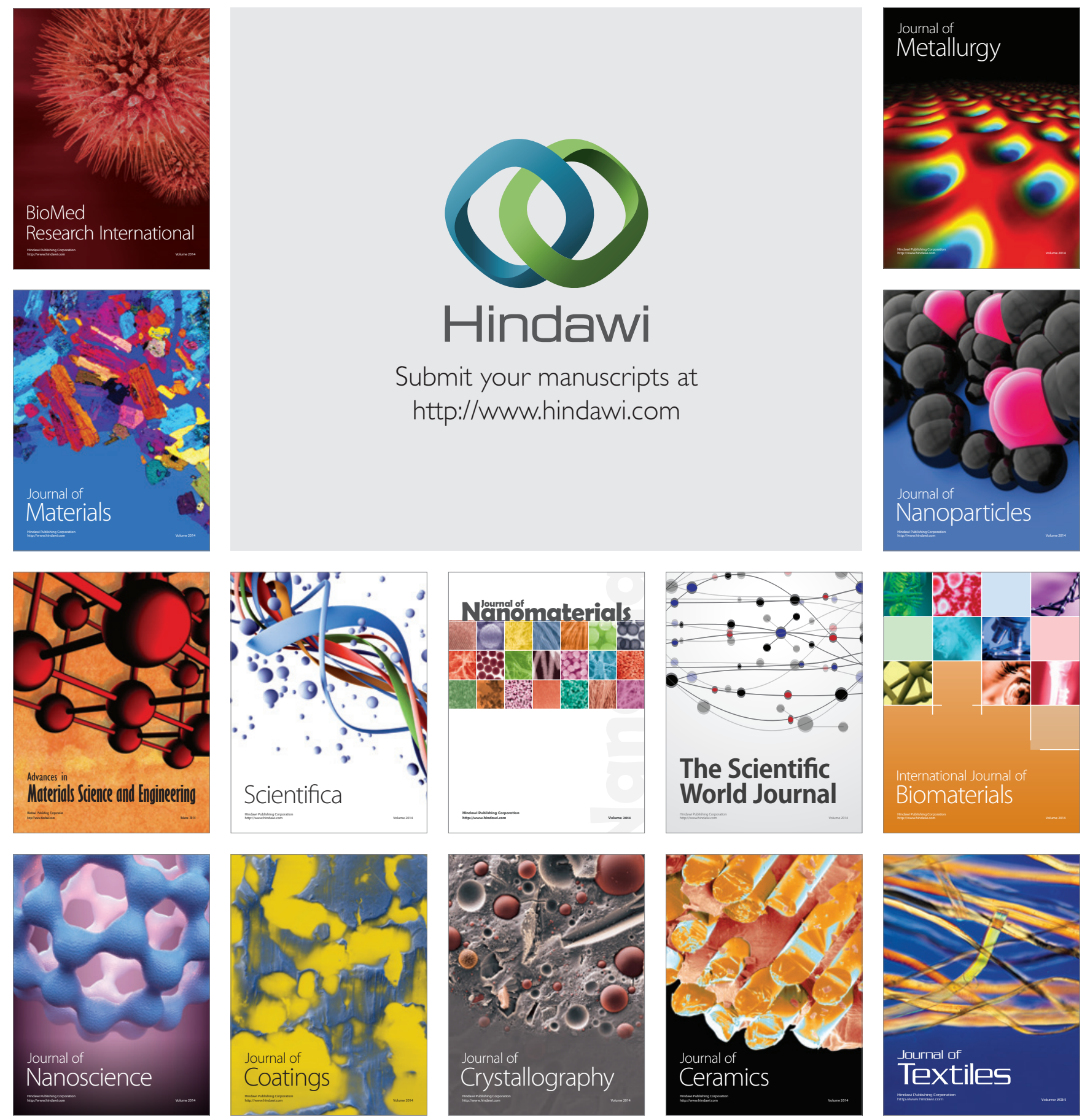